\title{
Patente como instrumento competitivo e como fonte de informação tecnológica
}

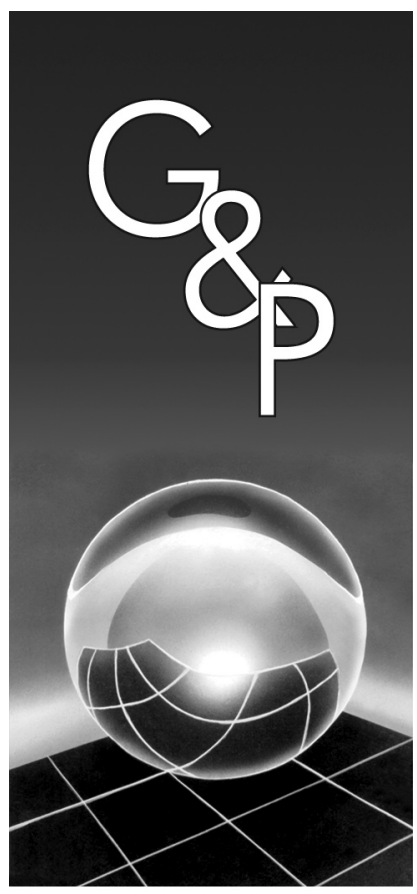

\author{
Ademir Antônio Ferreira \\ Edílson Rodrigues Guimarães \\ José Celso Contador
}

Resumo

Frente a um mercado globalizado, competitivo e repleto de inovações tecnológicas, as empresas brasileiras ainda não atentaram para a importância da utilização de patentes como instrumento competitivo, assim como não atentaram para a importância da exploração das patentes como fonte de informação tecnológica. Este artigo procura analisar esses aspectos da gestão da inovação e do desenvolvimento tecnológico através da realização de um trabalho de revisão bibliográfica sobre patentes e gestão de $C \&$ T e de pesquisa junto a empresas cadastradas na Associação Nacional de Pesquisa Industrial-ANPEI. Às empresas pesquisadas foi solicitado que respondessem a questões específicas sobre os fatores motivadores e os inibidores na utilização das patentes como instrumento competitivo e na exploração das patentes como fonte de informação tecnológica, procurando estabelecer, através de uma escala, o grau de importância de cada fator. Assim foi possível analisar estatisticamente a relevância de dez fatores motivadores e de dez fatores inibidores para a utilização das patentes como instrumento competitivo e como fonte de informação tecnológica, segmentando-se essa análise de acordo com o porte da empresa. Os resultados da pesquisa trouxeram evidências de que na área de gestão do conhecimento foi considerada como fator motivador mais relevante a possibilidade de recorrer aos documentos patentários publicados e, desse modo, perscrutar o "estado da arte" da pesquisa no setor. O fator inibidor mais relevante, tratando-se ainda a patente como fonte de informação tecnológica, foi considerada a falta de cultura com relação à pesquisa de tecnologia patenteada. Entretanto o maior desestímulo à utilização das patentes como um instrumento competitivo reside na atuação do órgão competente (INPI), principalmente com relação ao tempo de processamento de um pedido de patente. Na área de gestão estratégica, os fatores mais motivadores estão relacionados à obtenção de vantagens competitivas de um monopólio temporário concedido pela patente adquirida e à importância da criação do conceito de empresa inovadora. Em contrapartida, o surgimento de uma eventual tecnologia substituta num processo de difusão da informação é um fator inibidor porque pode vir a encurtar o período de rendimentos extraordinários propiciados pela patente.

Palavras-chave: Propriedade industrial. Patentes. Estratégia competitiva. Informação tecnológica.

\section{Introdução}

No campo da Ciência, Pesquisa e Tecnologia - CP \& T e, delimitando-o exclusivamente à área de estudos sobre o desenvolvimento tecnológico, este artigo observa o tema de "Patentes" e ressalta os resultados da pesquisa realizada junto a trinta e três empresas inovadoras vinculadas ao cadastro de afiliadas da Associação Nacional de Pesquisa, Desenvolvimento e Engenharia das Empresas Inovadoras - ANPEI (2005).

De modo geral, não se pode afirmar que tecnologia seja mera ciência aplicada, uma vez que ao longo dos tempos tem se colocado à frente dela, dispensando os conhecimentos precisos sobre como ou por que e conseguindo impor-se apenas pela eficácia de seu uso. Contudo, a tecnologia moderna baseia-se cada vez mais em ciência e na pesquisa científica aplicada. O conceito de tecnologia refere-se, então, à "soma de conhecimentos sobre meios e métodos usados para a produção de bens e serviços", e "inclui também os métodos de organização" (BANNOCK; BAXTER; REES, 1978).

Para Ferreira, Reis e Pereira (1997), tecnologia refere-se aos "sistemas operacionais adotados, equipamentos, engenharia do processo e do produto, desenvolvimento 
de pesquisa, métodos de trabalho etc.". Dessa maneira, tecnologia é capital e técnica: capital, entendido como meio de produção e como "ferramenta de produção que satisfaz às necessidades humanas de modo indireto" (NEMMERS, 1979), enquanto a técnica representa o conjunto de conhecimentos científicos aplicados ao trabalho.

Conforme Pinto e Fredes (1968), "a produção é o resultado do trabalho da população sobre a natureza, auxiliado pela tecnologia". Observando o fenômeno do crescimento econômico, o modelo de Solow (1957) evidencia que a poupança, o crescimento demográfico e - neste artigo, de especial interesse - o "progresso tecnológico" constituem as três condições para que possa haver desenvolvimento econômico (MANKIW, 1995). De maneira similar, Gwartney e Stroup (1995) citam três importantes fontes de crescimento para uma economia: "os investimentos em capital físico e humano, as melhorias na organização econômica e os avanços tecnológicos".

Indo além, ao considerar o contexto de uma firma e seu processo produtivo, pode-se afirmar que "a tecnologia de produção disponível determina a magnitude do produto gerado por determinadas quantidades de capital e trabalho" (MANKIW, 1995). Sendo assim, o resultado, em termos de produto final, para qualquer dada combinação entre quantidades desses dois fatores - bens ou serviços transformáveis em produção (CARVALHO, 1999) - representará o nível corrente de tecnologia disponível da organização naquele instante, estando a tal "capacidade tecnológica" implícita na função de produção como um fator auxiliar capaz de melhorar o nível de produtividade total.

Em outras palavras - mantidas constantes as quantidades dos fatores capital e trabalho, aos incrementos marginais sobre o nível de produtividade total dos fatores de produção da empresa -, dá-se o nome de desenvolvimento tecnológico apenas àqueles ganhos econômicos advindos da criação de valor obtido através de mudança da tecnologia, ou seja, das inovações tecnológicas absorvidas e aplicadas pela organização.

Dentre os trabalhos apresentados no "XVIII Simpósio de Gestão da Inovação Tecnológica” (1994), Baratelli, Leite, Costa e Vieira (1994) afirmam que "o processo de inovação representa a confluência de capacitação tecnológica e necessidades de mercado dentro do contexto da empresa inovadora".

Segundo a Fundação SEADE (2002), a inovação tecnológica corresponde à introdução, no mercado, de um produto (bem ou serviço) novo ou significativamente aperfeiçoado para a empresa ou à implementação de um processo novo ou significativamente aperfeiçoado dentro da empresa. A inovação baseia-se em resultados do esforço de um desenvolvimento de novas tecnologias ou novas combinações de tecnologias já existentes. A inovação deve ser nova para a empresa e não necessariamente para o mercado.
À medida que a invenção refere-se à descoberta de novos produtos ou processos, a inovação, por sua vez, é a aplicação econômica com sucesso dessas invenções através do uso prático e eficaz de novas técnicas, as quais podem ou não ter sido pesquisadas e desenvolvidas dentro da organização.

Entretanto, para garantir a apropriação dos resultados obtidos a partir do processo deliberado de inovações tecnológicas daquelas empresas que investiram em Pesquisa \& Desenvolvimento - incorrendo assim nos chamados gastos de P \& D -, a sociedade concede a essas organizações um método de proteção legal temporária, a patente. A patente permite a exploração da sua inovação em troca da informação detalhada sobre parte substancial do conteúdo técnico contido naquela matéria protegida por lei.

Dessa forma, o conhecimento tecnológico contido no "Documento de Patente" e disponibilizado no Banco de Patentes do Instituto Nacional de Propriedade Industrial INPI, é transformado então em informação pública, permanecendo, portanto, disponível para a consulta e a pesquisa de todos os interessados.

Enfim, a posse de uma patente possibilita remunerar a pesquisa científica e o desenvolvimento tecnológico, ao mesmo tempo em que gera estímulos nos agentes para que se movam na direção do crescimento econômico e possibilitem, assim, a elevação dos padrões de vida, trazendo a prosperidade para toda uma Nação. Sem as patentes, o compasso de desenvolvimento tecnológico diminuiria de ritmo.

Este trabalho aborda dois tópicos contidos no tema "Patentes": primeiro, o uso pelas empresas pesquisadas do documento de patente como uma fonte de informação tecnológica e, segundo, a utilização das patentes como um instrumento competitivo articulado com a estratégia da empresa.

O resultado da citada pesquisa distingue, dentre os vários fatores motivadores e inibidores, aqueles que mais sensibilizam as organizações e melhor evidenciam as decisões tecnológicas adotadas pelos administradores quando se considera o tema das patentes.

É importante ressaltar neste trabalho a utilização da Base de Dados ANPEI sobre Indicadores Empresariais em Inovação Tecnológica, uma vez que tal cadastro é também utilizado para a realização de uma família, reconhecidamente importante, de pesquisas como, por exemplo, a Pesquisa de Inovação Tecnológica - PINTEC, realizada de dois em dois anos pelo Instituto Brasileiro de Geografia e Estatística e alinhada à PIA - IBGE (pesquisa componente do mapa de pesquisas econômicas do Instituto, divulgada internacionalmente) e à pesquisa sobre Inovações Tecnológicas realizadas periodicamente pela Fundação SEADE, dentro de sua Pesquisa da Atividade Econômica Paulista (PAEP), com duas edições já realizadas em 1996 e 2001. 


\section{Patentes, informação tecnológica e competição}

Como visto anteriormente, o incentivo à ação inovativa e à continuidade empreendedora das organizações - tão importante para conduzir uma Nação ao crescimento econômico - depende, em muito, de garantias jurídicas contra aqueles imitadores que se arvoram em explorar ilegalmente suas eventuais inovações tecnológicas - sejam elas inventos, incrementos técnicos ou quaisquer demais criações industriais.

Um título de Propriedade Intelectual corresponde ao marco legal, mundo afora, no que se refere aos direitos relativos a determinados objetos intangíveis ou criações do intelecto humano. Na percepção de Lobo (1997), a propriedade intelectual "abrange, no domínio das artes e da ciência, os direitos relativos às produções literária, científica e artística, bem como, no campo industrial e comercial, os direitos que têm por objeto as invenções, os desenhos, as marcas de indústria e comércio, o nome comercial, as indicações geográficas, os segredos de fábrica, os dados proprietários e a repressão à concorrência desleal."

Segundo Silveira (1998), a criatividade do homem se exerce ora no campo da estética, ora no campo da técnica. Em consequência, a proteção jurídica também se dividiu em duas áreas: o Direito Autoral e, aqui de interesse, a Propriedade Industrial. Com relação a esta última, são reconhecidos como objetos de propriedade intelectual as seguintes criações intelectuais ou elementos de informação: soluções técnicas, aspectos de artigos utilitários (desenhos industriais) e signos ou símbolos distintivos (MORALES; CASTAÑóN, 1994).

Conforme a Organização Mundial de Proteção Intelectual OMPI (1993), o Instrumento de Proteção de Soluções Técnicas em questão subdivide-se entre: patentes, modelos de utilidades e desenhos (topografias) de circuitos integrados.

Relatado ainda na era da Antiga Grécia, o "Monopólio de Patente" foi instituído juridicamente como um

direito exclusivo concedido a indivíduos, por Elizabeth I (1533-1603) para produzir, importar ou comerciar uma mercadoria, que foi uma prática tornada ilegal na Inglaterra pela Lei dos Monopólios de 1624, até que em 1689 o poder concedente foi transferido do soberano para o Parlamento (SELDON; PENNANCE, 1975).

\subsection{A proteção das patentes}

No Brasil, a legislação sobre patentes surge com o Alvará de 1809, proclamado pelo então Príncipe Regente de Portugal Dom João:

parágrafo VI - Sendo muito conveniente que os inventores e introdutores de alguma nova máquina e invenção nas artes gozem do privilégio exclusivo, além do direito que possam ter ao favor pecuniário, que sou servido estabelecer em benefício da indústria e das artes, ordeno que todas as pessoas que estiverem neste caso apresentem o plano de seu novo invento à Real Junta do Comércio; e que esta, reconhecendo-lhe a verdade e fundamento dele, lhes conceda o privilégio exclusivo por quatorze anos, ficando obrigadas a fabricá-lo depois, para que, no fim desse prazo, toda a Nação goze do fruto dessa invenção.

No aparato da atual legislação brasileira, a Lei da Propriedade Industrial no ${ }^{\circ}$ 9.279/96, em vigor desde 15 de maio de 1997, substituindo a Lei 5772/71 e atualizada de acordo com a Lei 10.196/01, vigora em todo o território nacional.

A instituição concedente do direito de patente no Brasil é o citado INPI, autarquia federal vinculada ao Ministério do Desenvolvimento, Indústria e Comércio Exterior, signatária oficial de convênios com outros institutos outorgantes estrangeiros e representante legal do País nos foros internacionais e tratados de comércio multilaterais, como o TRIPs, o Acordo Mundial sobre aspectos dos direitos de propriedade industrial relacionados com o comércio. Trata-se do órgão brasileiro responsável pela concessão de patentes, registros de marcas, averbação de contratos de transferência de tecnologia e de franquia empresarial, e por registros de programas de computador, desenho industrial e indicações geográficas.

O Sistema de Proteção da Propriedade Industrial brasileiro confere a carta-patente em duas modalidades: 1) patente de invenção, concedida àquela invenção que atenda aos requisitos de novidade, atividade inventiva e aplicação industrial; e 2) patente de modelo de utilidade, concedida aos objetos que visem melhorar o uso ou utilidade dos produtos, dotando-os de maior eficiência ou comodidade na sua utilização, por meio de nova configuração, não necessitando que se obtenha uma nova concepção (SILVEIRA, 1998). A uma terceira modalidade, chamada Desenho Industrial, é concedido apenas um registro de propriedade.

No que se refere à aferição da efetiva novidade da matéria sujeita ao patenteamento, a lei pertinente considera que a invenção e o modelo de utilidade são "novos" quando não estiverem compreendidos dentro do "estado da técnica vigente"; este último constituído por tudo aquilo tornado acessível ao público antes da data de depósito do pedido de patente, por descrição escrita ou oral, por uso ou qualquer outro meio, no Brasil ou no exterior. Em outras palavras, por toda informação que já tenha sido publicada por qualquer meio, até o momento do depósito do pedido de patente.

Ainda pela legislação brasileira, a patente de invenção tem um prazo de proteção de vinte anos contados do depósito ou dez anos contados a partir da sua concessão, o que for maior. Para os modelos de utilidade, esses prazos caem para 15 e 7 anos, respectivamente. 
Uma vez concedida a outorga do direito de exclusividade temporária, o chamado Documento de Patente é publicado e incluído no Banco de Patentes do INPI, um acervo informacional contendo aproximadamente 32 milhões de referências entre documentos registrados pelos principais países industrializados, por organizações internacionais, além, naturalmente, da própria documentação brasileira.

Desde 2004, com a nova estrutura regimental implementada no INPI, o órgão administrador do Banco de Patentes, Centro de Divulgação, Documentação e Informação Tecnológica-CEDIN, passou a fazer parte da Diretoria de Articulação e Informação Tecnológica do INPI e se compôs em três divisões operacionais: de Informação Tecnológica, de Documentação e de Estudos e Programas.

Esse poderoso banco de dados gerido pelo CEDIN, abrangendo as informações industriais sobre o desenvolvimento de tecnologias para as quais se requer patente, fica então disponível para acesso público e oferece gratuitamente informações genéricas tais como um resumo do documento e os dados sobre a classificação no catálogo internacional de patentes.

Como corolário, ao desenvolverem suas pesquisas documentais e após terem selecionado o material relevante, os agentes interessados podem adquirir os documentos completos através do Banco de Patentes do INPI, e as informações industriais obtidas revelarão quase todo o estado da técnica sobre determinado assunto, além de delinearem as tendências da vanguarda tecnológica em questão.

Dentre as vantagens oferecidas pelas patentes pode-se citar, além dos incentivos ao desenvolvimento tecnológico, o encorajamento à pesquisa científica, à disseminação do conhecimento prático e econômico, à criação de novos mercados e à satisfação das necessidades latentes dos consumidores. Como ponto negativo, o uso do direito de patente significa, para estes últimos, preços mais elevados do que seria concebido sob um regime de concorrência perfeita.

Tendo o instituto da patente o objetivo de prover os inventores do direito de propriedade industrial sobre suas invenções e correspondendo ele à "outorga de direito exclusivo para uso de um processo específico ou para produção de um produto específico, durante um determinado período de tempo" (GWARTNEY; STROUP, 1995); o assim chamado Monopólio de Patente representa um benefício estratégico que as empresas inovadoras devem gerir e transformar em efetiva vantagem competitiva.

\subsection{O valor de uma patente}

Sendo o resultado econômico da aplicação de Pesquisa, Ciência e Tecnologia incorporado ao processo produtivo - e aqui entrando no campo da Gestão Empresarial e da Estratégia de Negócios -, a patente representa um ativo valioso e também um recurso competitivo à disposição das organizações, tendo em vista que propicia o domínio da exploração monopolística de dado produto ou processo produtivo, privilégio este capaz de criar ou adicionar valor à riqueza das empresas e de seus sócios.

Sempre que a organização trata o processo de inovação tecnológica de maneira deliberada e articulada, estabelecendo parâmetros e ações a fim de implementar e manter em atividade um Centro Tecnológico ou mesmo um pequeno departamento de $\mathrm{P} \& \mathrm{D}$, tal decisão de investimento implica um aumento em seus gastos e em seus dispêndios correntes. Por outro lado, espera-se que esses custos sejam recompensados por um fluxo de benefícios futuros, incertos in casu, porém de maior monta e que tornem rentável a atividade de pesquisa e desenvolvimento. Para as empresas, esse é o dilema interposto pelo risco característico dos investimentos em P \& D.

Nas empresas inovadoras que tenham concluído o processo de patenteamento e após a outorga pública de titularidade do direito temporário, podem elas excluir terceiros que não tenham sua prévia autorização daqueles atos relativos à produção e à comercialização do produto ou processo, resultado dos esforços próprios por elas empreendidos em P \& D e transformados em matéria intelectual protegida. Desse modo, a expressão do valor econômico da patente nas empresas será abrangida pelo monopólio concedido.

Tal instrumento de reserva de mercado permite uma proteção contra a concorrência efetiva e garante uma barreira legal à entrada de eventuais novos concorrentes, possibilitando a incorporação da chamada "margem de monopólio" em seus preços. Com efeito, restringida a "condição de entrada" às novas firmas - conforme abordado por Bain apud (Azevedo, 1999) -, encontra-se a firma patenteadora protegida por essa barreira institucional e habilitada a buscar para seus produtos, no mercado em que atua, a precificação que contemple um prêmio acima daquela média de lucratividade de longo prazo em sua indústria.

Ainda, é fato também que a patente assume para essas firmas inovadoras um valor moral - através do reconhecimento público como autora da invenção - e um significante valor patrimonial, derivado este último das vantagens pecuniárias obtidas com a inovação. É a ocorrência desse diferencial de preço - em outras palavras, desses rendimentos extraordinários ou royalties obtidos através da patente que permite às empresas titulares do direito exclusivo a possibilidade de aumentar seu nível patrimonial e melhorar sua posição estratégica.

No intuito de evidenciar o valor de uma patente deve-se procurar dentre os métodos de avaliação disponíveis os subsídios necessários para melhor estimar sua dimensão. Para tanto, o primeiro caminho é a verificação de seu valor contábil.

No Brasil, segundo a Lei 6.404/76 das Sociedades Anônimas, a rubrica "Patente" deve ser classificada no Balanço Patrimonial, capitalizada como um Ativo 
Imobilizado e, posteriormente, ter seu saldo monetário amortizado ao longo do período de vigência do direito. Com efeito, é de se observar que sob a rubrica patente o valor inscrito é quase sempre muito pequeno, já que ele apropria apenas os custos incorridos com os registros oficiais da propriedade industrial.

Uma vez que, segundo a legislação, os gastos em P \& D deverão ser lançados em conta própria do Ativo Diferido e amortizados como despesas no demonstrativo de resultados do mesmo período em que foram incorridos, à exceção de casos especiais como aqueles em que a organização tenha adquirido a patente de terceiros, o saldo dessa conta não representa seu efetivo valor para a empresa. Posto de outra maneira, a materialidade contábil das patentes é insuficiente quando se quer dimensionar seus benefícios efetivos.

Assim sendo, numa tentativa de melhor captar o valor desse ativo intangível, "fora-dos-livros", faz-se necessário lançar mão de outras técnicas de avaliação que permitam aproximação para chegar a um valor justo.

Uma alternativa poderia ser a consideração, quando possível, do valor de mercado da firma. A razão "Q de Tobin" pode trazer alguma luz para essa finalidade. Ao comparar a diferença entre o valor de mercado de uma firma e seu valor contábil ou "de livro", o resultado obtido corresponderá a um resíduo de valor não escriturado pelos registros contábeis. Em caso de resultar num resíduo positivo, esse sobre valor, isto é, um Fundo de Comércio (goodwill), englobará - dentre outros ativos intangíveis - o recurso tecnológico da patente.

Outra forma de valorizar a patente pode ser obtida analisando-se a curva de demanda da empresa e destacando o sobrepreço aplicado. Deve-se, então, descontá-lo pelo valor presente, utilizando a taxa requerida com base nos fluxos de caixa futuros dos prêmios, adicioná-lo aos fluxos eventualmente já realizados e, finalmente, confrontá-lo contra a soma dos gastos com P \& D acrescidos aos da patente. $\mathrm{O}$ valor resultante desse saldo representará o benefício líquido para a empresa trazido pela obtenção da outorga de uma patente.

Cumpre ressaltar ainda que, além dessas três formas mais objetivas de avaliação esboçadas acima, outras também devem ser destacadas. De fato, ao se considerar a dimensão estratégica da tecnologia para uma firma, outra forma de valor, de ordem subjetiva e mais sujeita às idiossincrasias da alta administração, assume um papel de destaque, como, por exemplo, quando se reconhece na patente um precioso valor estratégico, conforme conceituado pelo arcabouço VRIO de Barney (2002) ou pelas forças competitivas e pela cadeia de valor de Porter (1980, 1992).

\subsection{Utilizando as patentes como um instrumento competitivo}

Outro tópico abordado por este estudo sobre patentes trata também de um evento conjunto, relacionando, desta vez, a gestão da estratégia competitiva ao tema circunstanciado pelo método de proteção da propriedade industrial obtido através de uma patente.

De fato, quando se considera a dimensão estratégica da patente para uma firma, outra forma de valor, de ordem mais subjetiva e suscetível às idiossincrasias e à discricionariedade da alta administração das empresas, assume um papel de destaque: é quando então, sob uma outra perspectiva, cria-se, através do dispositivo da patente, um novo valor, o estratégico.

Ele surge no momento em que uma informação tecnológica transforma-se em um novo conhecimento e após um processo de "filtragem" - como nos termos colocados por Ansoff e McDonnell (1992) - transmuda-se numa informação estratégica, tornando-se um ativo patrimonial intangível capaz de ser aplicado como instrumento competitivo e de trazer benefícios econômicos, impactando assim a cadeia de valor da firma.

Trata-se de um processo de institucionalização do conhecimento filtrado pela empresa. Lançando mão de um método científico de gestão competitiva, insere-se aquela informação tecnológica na atividade de planejamento estratégico da firma. Um passo decisivo para qualquer mudança organizacional preconcebida, articulada e deliberada.

Numa outra instância, considerando as cinco forças competitivas que atuam em qualquer mercado (PORTER, 1980), a patente estende seus efeitos sobre o grau de rivalidade dentro da indústria e sobre o nível da barreira de entrada contra novos concorrentes, proporcionando àquelas empresas que obtiveram alguma inovação em "tecnologia proprietária" uma vantagem competitiva gerada a partir da atividade de apoio correspondente ao desenvolvimento tecnológico.

Ao mesmo tempo em que elimina a concorrência em sua Área Estratégica de Negócios - AEN, isto é, o segmento de atuação da empresa, a patente também aumenta o poder de barganha de seu detentor em relação aos consumidores. Assim, é possível à firma extrair um benefício adicional - em termos de rentabilidade e pelo prazo de duração do direito concedido - acima do valor da lucratividade média de mercado, caso ela participasse de uma estrutura industrial em concorrência perfeita. A patente se coloca aí como um conducto para a almejada Posição Competitiva Superior.

Ainda segundo Porter (1980), uma transformação tecnológica aumenta a vantagem competitiva caso resulte em custo mais baixo ou em diferenciação e, ainda, se "puder ser protegida contra imitações". Dessa forma, avançando além da teoria de Porter (1980) com sua análise das cinco forças competitivas atuantes em qualquer indústria (1980) e dos elementos componentes da cadeia de valor de uma empresa (1985), chega-se ao arcabouço da Visão Baseada em Recursos (RBV) delineada por Barney (2002), segundo a qual a posse de recursos organizacionais raros e valiosos pode ser fonte de vantagem competitiva no longo prazo para uma empresa. 
Destaca-se aqui, dentre as quatro perguntas básicas colocadas pela chamada Análise Valor, Raridade, Imitabilidade e Organização - VRIO de Barney (2002), aquela que inclui em seu escopo o tema das patentes. Refere-se ela à questão da imitabilidade, a qual é assim formulada pelo autor: quando comparadas àquelas firmas que já possuem determinado recurso, as firmas que não o possuem devem incorrer em desvantagem de custo para obtê-lo?

De fato, conforme Collis e Montgomery (1995), um recurso ou capacidade inimitável, quando utilizado estrategicamente por uma firma, tem boas chances de significar uma corrente de lucros sustentável ao longo do tempo.

Assim sendo, no sentido de conduzir apropriadamente qualquer avaliação estratégica interna sobre uma firma, e levando em consideração os pressupostos de heterogeneidade e de imobilidade dos recursos próprios sobre o conjunto de seus pontos fortes e fracos, a teoria de Barney (2002) alude, dentre outros elementos, à ocorrência da chamada tecnologia proprietária.

Em relação à área da Gestão do Conhecimento de uma organização, o resultado patrimonial obtido pelo desenvolvimento de pesquisas e das criações tecnológicas nessas firmas inovadoras precisa ser protegido contra imitadores, seja através do sigilo industrial, seja pelo método de proteção formal da patente sobre um dado produto ou processo.

O conceito de tecnologia proprietária - patenteada ou de sigilo industrial - refere-se ao nível de custo em que os concorrentes de uma firma devem incorrer para que possam replicar ou substituir os recursos valiosos e raros da titular, criando a chamada 'tecnologia substituta', ou mesmo, simplesmente, copiando o recurso da firma 'incumbente'. Ocorra que esses custos de imitação sejam superiores aos da empresa proprietária e haverá, por definição, uma vantagem competitiva sustentável que não poderá ser quebrada no curto prazo por essas concorrentes.

Para Barney (2002), em se tratando das oportunidades latentes no ambiente industrial, as vantagens em ser o 'primeiroa-se-mover' num segmento e estabelecer uma estratégia de liderança tecnológica pode levar a empresa inovadora a ocupar posições competitivas superiores. O prazo durante o qual a empresa poderá manter-se em determinada posição depende de diversos fatores, dentre os quais a capacidade empresarial de proteger essa informação estratégica.

Aqui, diferentemente do sigilo industrial, o método protetivo das patentes garante uma exclusividade na exploração do recurso, e geralmente representa um alto custo de imitação em termos de processos legais contra eventuais copiadores, inibindo sua ação deletéria. Por outro lado, com a publicação do conhecimento técnico da patente pelo órgão competente - no Brasil, o INPI -, a informação estratégica torna-se pública e facilita o aparecimento de tecnologia substituta.
As firmas concorrentes ou os novos entrantes utilizam-se para tanto de um processo deliberado de pesquisa e desenvolvimento baseado em métodos de engenharia e arquitetura reversa, Inteligência Competitiva (FERNANDES, 2001), Espionagem Industrial e técnicas da teoria do Mosaico.

Desse modo, segundo Barney (2002), se a patente por certo aumenta o poder competitivo das empresas propiciando-lhes uma vantagem em termos de lucratividade, ela também pode encurtar o prazo de duração do privilégio conquistado ao ser um 'primeiro-a-se-mover' na indústria, abreviando a sustentabilidade da vantagem competitiva.

Portanto, é sobre esse tema de considerável relevância que se debruçou a pesquisa de campo realizada, que envolveu elementos contidos em duas áreas do estudo da Teoria das Organizações: a de Gestão do Conhecimento - observando nuances sobre a questão do uso de informação tecnológica pelas empresas como um insumo no processo de pesquisa, desenvolvimento e posterior proteção pelo método de patenteamento de suas invenções e inovações - e a Estratégia Competitiva, envolvendo questões relativas à eventual aplicação das patentes como instrumento competitivo, articulado a uma estratégia empresarial non-naïve e acaso contemplado nas diretrizes e política de negócios de algumas das mais importantes empresas inovadoras no Brasil.

\section{A Pesquisa sobre patentes}

Considerando a delimitação dos dois tópicos em destaque, a pesquisa realizada buscou respostas para quatro indagações básicas, que nortearam o trabalho e resumem os objetivos da pesquisa:

- Quais fatores motivam as organizações a explorar as patentes como fonte de informação tecnológica? Quais fatores a inibem?

- Quais fatores motivam as organizações a utilizar as patentes como um instrumento competitivo? Quais fatores a inibem para isso?

Desse modo, o objetivo declarado pela pesquisa foi o de identificar e avaliar tanto aqueles fatores motivadores como os fatores inibidores envolvidos no processo de decisão estratégica das empresas a respeito da exploração da informação pública contida nos documentos de patentes disponibilizados pelo banco de patentes do INPI como uma fonte para desenvolvimento de pesquisa, e também como forma de evidenciar complementarmente a utilização das patentes como um instrumento competitivo e como uma variável estratégica presente nos planos das empresas.

Ainda dentro desse contexto, dois propósitos acessórios foram consignados na pesquisa:

- analisar a relevância dos fatores motivadores e inibidores da exploração das patentes como fonte de informação tecnológica e sua utilização como instrumento competitivo, e 
- analisar a sensibilidade das empresas tomadas em seus diferentes tamanhos ou portes, quando se observa a exploração das patentes como fonte de informação tecnológica e de sua utilização como instrumento competitivo.

\subsection{Metodologia da pesquisa}

Tendo em vista o objetivo declarado, o trabalho começou pela identificação dos principais fatores motivadores e dos principais fatores inibidores. Para tanto, foram realizadas entrevistas preliminares junto a empresários e a agentes da propriedade industrial e especialistas no assunto, complementada por uma revisão na literatura nacional e internacional.

A pesquisa foi realizada nos moldes de um estudo descritivo, com interpretação estatística dos dados, enquanto o universo da pesquisa foi composto pelas empresas que responderam ao questionário anual de 1999 da ANPEI (1999).

A coleta de dados foi feita por meio de questionário em forma eletrônica ou impressa, em escala de quatro níveis, partindo-se da negação de qualquer impacto do fator pesquisado sobre a decisão empresarial em favor do uso da patente e graduando-se as respostas afirmativas à pergunta entre o pouco relevante, relevante ou muito relevante que impactou sua escolha. Tal questionário foi estruturado em três blocos:

- primeiro bloco, destinado à coleta de dados do respondente e do nível de conhecimento que possui sobre o sistema de patentes,

- segundo bloco, destinado à avaliação dos fatores motivadores e

- terceiro bloco, à avaliação dos fatores inibidores.

As respostas ao questionário eletrônico foram automaticamente gravadas em uma base de dados e as do questionário impresso, digitadas. Essa base de dados facilitou o cruzamento das informações e a análise das informações de acordo com o porte das empresas.

Para verificar a existência de diferença significativa entre as médias das respostas das empresas classificadas pelo porte, foi aplicado o teste "t", adotando o nível de significância de 5\%. Para análise comparativa por tamanho ou porte de empresas foi criado um programa a partir do aplicativo para banco de dados Microsoft Access.

\subsection{As unidades de pesquisa - empresas inovadoras}

O cadastro de empresas da ANPEI é constituído pelas organizações que estejam de alguma forma envolvidas no processo de inovação. Essa plataforma de dados apresenta uma base comum de organizações responsáveis por importantes pesquisas nacionais na área do desenvolvimento tecnológico.
Na última pesquisa de $\mathrm{P} \& \mathrm{D}$ divulgada pela ANPEI em 2004, foram pré-selecionadas duas mil, sendo a amostra final constituída por 319 empresas respondentes, as quais apresentaram, em média, uma receita anual bruta de aproximadamente $\mathrm{R} \$ 600$ milhões e 1173 funcionários.

Por proposta do Ministério da Ciência e Tecnologia (MCT), atualmente a Pesquisa da ANPEI estabeleceu parceria na elaboração e aplicação do questionário de pesquisa, sendo o instrumento desenhado em conjunto com a Fundação SEADE e revisto pelo IBGE. A Fundação SEADE fornece também apoio técnico e operacional nas fases referentes à coleta, crítica, consistência e tabulação dos resultados da pesquisa ANPEI sobre indicadores empresariais de $\mathrm{P} \& \mathrm{D}$.

Este trabalho utilizou essa mesma plataforma de dados sobre empresas inovadoras - ano-base 1999 - e analisou diferentes aspectos do fenômeno das patentes, numa abordagem não adotada por nenhuma das duas pesquisas acima. Dessa forma, a sua maior relevância encontra-se no fato de não remontar ou duplicar informações desnecessárias, mas deter-se em aspectos capazes de potencializar o espectro das pesquisas realizadas, complementando os trabalhos empreendidos por outras Instituições.

Tratando-se dos sujeitos da pesquisa e, portanto, no âmbito das 33 empresas - todas elas organizações inovadoras pertencentes ao setor manufatureiro - este trabalho sobre patentes apresentou uma configuração por áreas de atuação das firmas respondentes assim distribuída: onze empresas (33,3\%) da área de Mecânica e Metalurgia, outras onze do setor Químico, quatro $(12,1 \%)$ do setor de Eletrônica e sete firmas $(21,2 \%)$ classificadas como outras áreas de atuação.

\section{Resultados obtidos}

\subsection{O perfil das empresas}

Numa análise geral, o perfil das organizações pesquisadas pode ser descrito a partir da verificação das respostas para as quatro perguntas apresentadas no primeiro bloco do questionário.

Todas as empresas confirmaram que conhecem o assunto e a utilidade de uma patente, todavia, somente 28 delas, ou $85 \%$ do total, confirmaram já ter completado um processo de obtenção de patente. Por outro lado, $91 \%$ do total - ou seja, 30 empresas - exploram a patente como fonte de informação tecnológica e 75\% utilizam-na como instrumento competitivo na formulação de sua estratégia.

Após essas considerações centrais, numa extensão da análise geral, a pesquisa segmentou as trinta e três firmas componentes do cadastro da ANPEI em quatro extratos, de acordo com seu tamanho ou porte (utilizando o critério do número de funcionários), conforme exibido na Tabela 1.

Deve ser observado que, no caso das empresas que possuem mais de 500 funcionários, esse grupo assim estratificado no cadastro ANPEI foi subdividido entre dois 
extratos separados: o das "grandes empresas", propriamente dito, e ainda outro grupo de especial relevância para este trabalho, o das "megaempresas". Após a apuração das respostas dos questionários, verificou-se o fato de que todas as sete empresas com pessoal ocupado acima de 5000 trabalhadores responderam a todas as questões pesquisadas, tornando-se, assim, uma fonte de dados mais completa e justificando uma análise separada.

\subsection{Explorando as patentes como uma fonte de informação tecnológica}

Numa análise mais ampla e geral, considerou-se apenas a carga fatorial de cada atributo informacional e estratégico, independentemente do porte dos elementos pesquisados e, numa segunda análise, além de observar a carga dos fatores motivadores e inibidores, fez-se ainda um cruzamento desses atributos, contrapondo-os a cada um dos quatro grupos de elementos classificados pelo porte.

A análise e interpretação dos fatores motivadores foram feitas por meio do teste " $t$ " com a finalidade de verificar a existência de diferenças significativas entre as médias, teste aplicado da maior média para a menor e da menor média para a maior sempre adotando nível de significância de 5\%, obtendo-se assim três grupos:

1. mais motivador: formado pelas médias que não possuem diferenças significativas entre si (da maior para a menor), menos as médias do grupo intermediário, obtendo o intervalo 3,84 a 4,19;

2. menos motivador: formado pelas médias que não possuem diferenças significativas entre si (da menor para a maior), menos as médias do grupo intermediário, obtendo o intervalo 3,36 a 3,81; e

3. formado pela intersecção das médias que fazem parte dos dois grupos quando aplicado o teste " $\mathrm{t}$ " da maior média para a menor e da menor para a maior, obtendo o intervalo 3,81 a 3,84 .

Dessa forma, identificaram-se os seguintes fatores como mais motivadores para a exploração das patentes como uma fonte de informação tecnológica:

- intenção de investir no que pode ser efetivamente novo e evitar eventual infração de patentes alheias,

- obtenção de maior conhecimento sobre tecnologias, produtos e processos desenvolvidos,

Tabela 1. Porte das empresas respondentes.

\begin{tabular}{lcc}
\hline \multicolumn{1}{c}{ Porte das empresas } & Quant. & \% \\
\hline Pequenas empresas (até 99 funcionários) & 6 & 18,2 \\
Médias empresas (até 499 funcionários) & 12 & 36,4 \\
Grandes empresas (até 4999 funcionários) & 8 & 24,2 \\
Megaempresas (5000 funcionários ou mais) & 7 & 21,2 \\
Total & 33 & 100,0 \\
\hline
\end{tabular}

Fonte: Autores.
- utilização do documento de patente em pesquisa e desenvolvimento, evitando duplicação de esforços, ou seja, pesquisar algo que faça parte do estado da técnica, além da

- consideração do documento de patente como um eficiente meio de informação tecnológica.

Pode-se observar que os fatores mais motivadores mantêm uma relação em comum, que é a obtenção de informação tecnológica para ser utilizada em pesquisa e desenvolvimento. Deve ser ressaltado que, embora "o interesse em obter uma pesquisa direcionada, com base numa Classificação Internacional", tenha resultado num dos fatores menos motivadores, também se revelou como o de maior grau de desconhecimento por parte das empresas.

Ao testar os aspectos inibidores que desestimulam a exploração das patentes como uma fonte de informação tecnológica, discriminaram-se como os mais importantes:

- a falta de cultura com relação à pesquisa de tecnologia patenteada e

- o custo e o tempo envolvidos na pesquisa de documentos de patentes.

A Tabela 2 apresenta o grau de exploração das patentes como fonte de informação tecnológica em cada segmento pesquisado e pode ajudar a explicar por que $33,3 \%$ das pequenas empresas e $14,3 \%$ das megaempresas consideram inibidor o custo e o tempo envolvidos na pesquisa de documentos sobre patentes.

O "custo e o tempo envolvidos na pesquisa", alegado pelos respondentes, pode evidenciar pouca intimidade do entrevistado com o assunto, visto que a busca de patentes via base de dados pode não ser cara, mas exige profissional qualificado e dedicado ao tema. As informações estão disponíveis aos interessados e o sistema de classificação internacional permite uma busca rápida e eficiente nos documentos de patentes o que reduz efetivamente o custo e o tempo envolvidos nessas pesquisas, sem considerar ainda os benefícios e as diversas vantagens de se obter informações tecnológicas através das patentes.

Para as empresas, no que se refere à exploração de patentes como uma fonte de informação tecnológica, quais fatores se tornam mais importantes: os motivadores ou os inibidores? Com o intuito de responder a essa questão, comparou-se a relevância dos fatores motivadores confrontando-os aos

Tabela 2. Grau de exploração das patentes como fonte de informação.

\begin{tabular}{lccccc}
\hline \multicolumn{1}{c}{ Porte } & Não & Pouco & Sim & Plenamente & Total \\
\hline Pequenas empresas & 33,3 & 50,0 & 16,7 & 0 & 100 \\
Médias empresas & 0 & 25,0 & 50,0 & 25,0 & 100 \\
Grandes empresas & 0 & 25,0 & 50,0 & 25,0 & 100 \\
Megaempresas & 14,3 & 0 & 42,9 & 42,9 & 100 \\
\hline
\end{tabular}

Fonte: Autores. 
inibidores, buscando verificar se haveria diferença significativa entre a média dos fatores motivadores em relação àquela dos inibidores. A média dos fatores motivadores apresentou um score de 3,78, enquanto a dos inibidores foi igual a 3,05. Aplicado o teste " $\mathrm{t}$ " de Student, constatou-se a ocorrência de uma diferença significativa entre as duas séries de scores, evidenciando que os aspectos motivadores são mais relevantes do que os inibidores.

\subsection{Diferenças de sensibilidade entre empresas de diferentes segmentos}

No intuito de esclarecer quais fatores seriam mais sensíveis ao porte da empresa e assim estabelecer distinções entre os grupos considerados, foram assinaladas, para cada fator, além da maior, também a menor proporção de respostas. Como complemento, foram selecionados em seguida aqueles fatores com a maior diferença.

Conforme a Tabela 2, apesar de $75 \%$ das médias e grandes empresas e de 85,8\% das megaempresas explorarem relativa ou plenamente a patente como uma fonte de informação tecnológica, observaram-se as frequentes citações de documentos de patentes americanas, o que denota a realização de efetivas pesquisas nas bases de dados.

Ao se tratar dos aspectos motivadores mais relevantes para a exploração das patentes como uma fonte de informação tecnológica, constatou-se que, em relação às megaempresas, os fatores mais relevantes foram: "obter maior conhecimento sobre tecnologias, produtos e processos desenvolvidos" e "utilizar o documento de patente em pesquisa e desenvolvimento, evitando duplicação de esforços, ou seja, pesquisar algo que faça parte do estado da técnica".

Para as grandes empresas, o fator mais relevante foi, "avaliar as oportunidades de mercado com mapeamento de tecnologias passíveis de aquisição ou licenciamento".

Para as médias e para as pequenas empresas, este também foi considerado um fator relevante, aliado ao fator, "considerar o documento de patente como um eficiente meio de informação tecnológica".

Com relação aos aspectos inibidores mais relevantes na exploração das patentes como fonte de informação tecnológica, verificou-se que os fatores destacados no caso das consideradas megaempresas, foram a "falta de conhecimento do próprio sistema de patentes" e o "desconhecimento dos recursos disponíveis na base de dados do INPI e em outras bases de dados gratuitas disponíveis na Internet".

Os fatores citados pelas grandes, médias e pequenas empresas foram a "falta de cultura com relação à pesquisa de tecnologia patenteada" e o "custo e tempo envolvidos nas pesquisas em documentos de patentes", sendo que as pequenas empresas também consideraram o fator "desconhecimento dos recursos disponíveis na base de dados do INPI e em outras bases de dados gratuitas disponíveis na Internet".

\subsection{Patente como instrumento competitivo}

Usando os mesmos procedimentos técnicos que foram aplicados na seção referente à exploração das patentes como uma fonte de informação tecnológica, também aqui foram obtidos os fatores motivadores mais significativos para a utilização das patentes como um instrumento competitivo.

$\mathrm{Na}$ análise geral dos dados obtidos, os fatores mais relevantes apontados pelos respondentes foram:

- a busca por acrescentar credibilidade ao produto e contribuir para a criação do conceito de empresa inovadora,

- a intenção de obter um monopólio temporário através da patente e, consequentemente, poder excluir terceiros de fabricarem, usarem, venderem ou importarem a invenção e

- a proteção do investimento em novas tecnologias, garantindo uma rentabilidade superior ao capital empregado no uso de tecnologias conhecidas.

- Quando se trata dos aspectos inibidores que desestimulam a utilização das patentes como um instrumento competitivo, o fator claramente destacado foi a situação do órgão competente (INPI), principalmente com relação ao tempo de processamento de um pedido de patente. Esse fator foi considerado o mais inibidor da utilização das patentes como instrumento competitivo, mas não está diretamente relacionado aos aspectos tecnológicos ou científicos do processo. Reflete uma crítica à situação em que o INPI se encontra, principalmente com relação ao tempo de processamento de um pedido de patente, o que retarda o exercício dos direitos conferidos pela patente.

Para se contrapor a importância dada pelas empresas pesquisadas entre os fatores motivadores quando comparados aos inibidores, também neste caso foi verificado se as diferenças entre a média dos dois atributos eram significantes. Ocorre que a média dos fatores motivadores foi 3,85 , enquanto a dos inibidores foi de 3,41 pontos. Aplicado o teste "t" de Student, constatou-se terem os fatores motivadores o mesmo padrão de relevância dos fatores inibidores.

Com efeito, no intuito de ressaltar as diferenças de sensibilidade entre empresas de diferentes portes, também para este tópico sobre utilização das patentes como instrumento competitivo, elaborou-se a Tabela 3, que contém a distribuição das respostas de cada grupo de empresas selecionado:

\subsection{Diferenças de sensibilidade entre empresas de diferentes portes}

Com relação aos Aspectos motivadores mais relevantes para a utilização das patentes como um instrumento competitivo nesta segunda modalidade de análise, para o 
caso das megaempresas, os fatores mais relevantes foram: "a busca para obter um monopólio temporário através da patente e consequentemente poder excluir terceiros de fabricarem, usarem, venderem ou importarem a invenção", e ainda, "para acrescentar credibilidade ao produto e contribuir para a criação de um conceito de empresa inovadora".

Para as grandes empresas, "conquistar uma maior participação no mercado e obter a proteção oferecida pela patente" revelou-se mais significante.

Já para as empresas médias, além do fator relativo à maior participação no mercado, foi considerada uma importante motivação o fator "acrescentar credibilidade ao produto". E para as pequenas firmas, obter um monopólio temporário através da patente, bem como proteger o investimento em novas tecnologias, foram os fatores mais relevantes citados.

No que se refere aos aspectos que inibem a exploração das patentes como um instrumento competitivo citado pelas megaempresas, destacam-se como fatores mais relevantes "a falta de cultura com relação à propriedade industrial", "a falta de credibilidade no sistema judiciário" e "a situação do órgão competente, o INPI".

Para o segmento das grandes firmas, a falta de cultura e de conhecimento sobre a propriedade industrial e os direitos conferidos pelas patentes foi o aspecto considerado mais inibidor.

A "falta de uma política direcionada para a pesquisa e desenvolvimento", além da "falta de cultura com relação à propriedade industrial" e do "custo a se incorrer para agir judicialmente contra terceiros" foram os fatores reverenciados entre as firmas de médio porte. No âmbito das empresas pequenas, todos os fatores citados nos outros extratos foram também considerados, exceto o que se refere ao INPI. Essa resposta demonstra coerência com o fato de que 33,3\% das empresas de pequeno porte nunca solicitaram depósitos de patentes no INPI e as restantes não efetuaram mais do que dez solicitações ao órgão. Todavia, "o custo para obter e manter uma patente" foi considerado um fator inibidor pelo grupo de pequenas empresas.

\section{Conclusões e recomendações finais}

Ao considerar o porte da firma na análise, a pesquisa destacou as diferenças na sensibilidade manifestada entre os quatro grupos de firmas estratificadas por porte. Essa

Tabela 3. Grau de utilização estratégica das patentes.

\begin{tabular}{lccccc}
\hline \multicolumn{1}{c}{ Porte } & Não & Pouco & Sim & Plenamente & Total \\
\hline Pequenas empresas & 50,0 & 33,3 & 16,7 & 0 & 100 \\
Médias empresas & 16,7 & 25,0 & 50,0 & 8,3 & 100 \\
Grandes empresas & 25,0 & 25,0 & 25,0 & 25,0 & 100 \\
Megaempresas & 14,3 & 0 & 71,4 & 14,3 & 100 \\
\hline
\end{tabular}

Fonte: Autores. decisão trouxe evidências de que o tamanho da empresa conduz a distintas percepções sobre que fatores podem ser mais motivadores ou mais inibidores, sugerindo, portanto, que algumas informações pertinentes à propriedade industrial das patentes devam ser tratadas de forma específica para cada extrato.

Com relação à análise comparativa entre os fatores estimulantes e os inibidores na utilização de patentes, esta indicou, como se pode observar na Tabela 4, que os fatores motivadores foram quantitativamente mais relevantes do que os inibidores, uma vez que apresentam uma carga fatorial maior.

Ao focalizar a análise geral dos fatores e restringindo-se ao contexto das duas áreas do campo de Gestão Organizacional revisitadas, a pesquisa trouxe algumas evidências sobre quais fatores motivadores e quais inibidores mais discriminam para o conjunto de empresas inovadoras respondentes.

Entende-se primeiramente que tais fatores podem induzir ou desestimular uma firma à exploração do conhecimento técnico contido nas patentes obtidas por terceiros como uma valiosa fonte de informação tecnológica, de baixo custo e capaz de alimentar uma empresa inovadora em sua própria atividade de pesquisa e desenvolvimento de novos produtos e processos.

Levando-se em conta a área de Gestão do Conhecimento, o fator mais relevante apontado pelos números da Tabela 4 é a motivação declarada pelas empresas inovadoras pesquisadas em recorrer aos documentos patentários publicados para, desse modo, perscrutar o estado da técnica vigente em sua área estratégica e obter maior conhecimento sobre tecnologias, produtos e processos desenvolvidos por terceiros. Somente $6 \%$ de um total de 32 respostas consideraram esse fator como não motivador para o uso da informação tecnológica contida nos documentos de patente, enquanto $87 \%$ deles consideraram-no relevante e muito relevante.

Com relação ao fator inibidor mais relevante, tratando-se ainda a patente como uma fonte de informação tecnológica, "a falta de cultura com relação à pesquisa de tecnologia patenteada" foi o que mais se destacou, embora percentualmente tenha se mostrado pouco expressivo.

$\mathrm{Na}$ área da Gestão Estratégica, por outro lado, o mesmo procedimento de análise geral dos fatores foi adotado, mas, de maneira diversa, considerou-se a eventual inserção do recurso inimitável da patente como um instrumento competitivo incorporado ao processo de planejamento organizacional.

Contudo, posicionado numa região de interface entre as duas áreas de estratégia e conhecimento, o fator considerado de maior desestímulo à utilização das patentes como um instrumento competitivo foi a situação do órgão competente (INPI), principalmente com relação ao tempo de processamento de um pedido de patente. Esse tempo - em média oito anos à época - retarda a execução dos direitos 
Tabela 4. Grau de utilização estratégica das patentes.

\begin{tabular}{|c|c|c|c|c|c|c|}
\hline Área & Tópico & Fator & Não & $\begin{array}{c}\text { Pouco } \\
\text { relevante }\end{array}$ & Relevante & $\begin{array}{c}\text { Muito } \\
\text { relevante }\end{array}$ \\
\hline Gestão Estratégica & $\begin{array}{l}\text { Instrumento } \\
\text { Competitivo }\end{array}$ & $\begin{array}{c}\text { Obtenção de um monopólio } \\
\text { temporário e exclusão de terceiros } \\
\text { Motivador }\end{array}$ & 13 & 19 & 35 & 46 \\
\hline Gestão Estratégica & $\begin{array}{l}\text { Instrumento } \\
\text { Competitivo }\end{array}$ & $\begin{array}{c}\text { Acrescentar credibilidade ao } \\
\text { produto e conceito de empresa inovadora } \\
\text { Motivador }\end{array}$ & 3 & 14 & 47 & 39 \\
\hline $\begin{array}{l}\text { Gestão do } \\
\text { Conhecimento }\end{array}$ & $\begin{array}{l}\text { Informação } \\
\text { Tecnológica }\end{array}$ & $\begin{array}{c}\text { Obter maior conhecimento } \\
\text { sobre tecnologias patenteadas } \\
\text { Motivador }\end{array}$ & 6 & 13 & 40 & 47 \\
\hline Gestão Estratégica & $\begin{array}{l}\text { Instrumento } \\
\text { Competitivo }\end{array}$ & $\begin{array}{c}\text { Tempo de processamento } \\
\text { de um pedido de patente no INPI } \\
\text { Inibidor }\end{array}$ & 20 & 21 & 46 & 33 \\
\hline $\begin{array}{l}\text { Gestão do } \\
\text { Conhecimento }\end{array}$ & $\begin{array}{l}\text { Informação } \\
\text { Tecnológica }\end{array}$ & $\begin{array}{c}\text { Falta de cultura com relação } \\
\text { à pesquisa tecnológica patenteada } \\
\text { Inibidor }\end{array}$ & 23 & 39 & 31 & 30 \\
\hline
\end{tabular}

Fonte: Autores. (*) Percentual sobre o total de respostas válidas.

conferidos por uma patente, uma vez que tais direitos somente poderão ser exigidos após sua concessão oficial. Em função disso, com o alongamento no prazo de espera pela patente e a externalização do conhecimento tecnológico, as empresas inovadoras podem ver aumentar seu risco relativo à proteção do sigilo industrial.

Já comentamos anteriormente que, diferentemente dos demais fatores que representam oportunidades oferecidas pelo ambiente, esse fator aparece como uma ameaça interposta às firmas pela ineficiência da estrutura institucional do País, agindo como uma variável independente e exógena.

Também representando uma oportunidade ambiental e de novo envolvendo os recursos internos da firma, o fator mais motivador para a utilização das patentes como um instrumento estratégico está relacionado à obtenção de vantagens competitivas: $46 \%$ dos respondentes consideraram muito motivadora a obtenção de um monopólio temporário através da patente e, consequentemente, a possibilidade de excluir terceiros de fabricarem, usarem, venderem ou importarem a invenção.

Outra vez, no que se refere à importância da criação do conceito de empresa inovadora, volta-se à questão da inimitabilidade dos recursos internos da firma como um dos pressupostos para que ela obtenha vantagem competitiva que possa ser sustentada no longo prazo. Com efeito, a partir da publicação do conhecimento tecnológico inédito e da garantia do direito patentário, a emergência de uma eventual tecnologia substituta surgida num processo de difusão da informação pode vir a encurtar o período de rendimentos extraordinários propiciados pela patente.

Segundo Barney (2002), reafirmando trabalho acadêmico de apud Mansfield, Schwartz e Wagner (1981), grande parte das patentes pesquisadas foram legalmente imitadas em quatro anos, sendo tal afirmação mais verdadeira para as inovações de produto. Afirma o autor que à exceção de algumas indústrias, como a farmacêutica... as patentes, per se, raramente são uma fonte de vantagem competitiva sustentável para as firmas.

Essa ameaça - de que, ao ser publicada, a informação tecnológica possa causar uma queda nos custos de imitação dos concorrentes e entrantes, assim conduzindo a uma eventual diminuição no prazo ou no nível dos lucros superiores da firma titular da patente - pode também ser enfrentada, segundo o mesmo autor, através das habilidades de gestão e de coordenação da empresa inovadora. Capacidades que, por sua vez, também podem ser fontes de vantagem competitiva sustentável. Barney (2002) cita como exemplo, o processo de inovação contínua de produtos aplicada pelas empresas japonesas na indústria de eletrônicos, as quais conseguem manter um nível estável de sustentabilidade para suas vantagens de escopo, apesar das imitações a que estão sujeitas cada uma das inovações em separado.

Como mais podem as empresas inovadoras enfrentar tal ameaça?

Debruçar-se sobre isso conduz à quarta pergunta formulada pela abordagem VRIO:

A firma está organizada para explorar o completo potencial competitivo de seus recursos e capacidades?.

Para as organizações detentoras de patentes, isso ocorreria no bojo de um processo de institucionalização da informação tecnológica contida na própria patente proprietária, de maneira que sua perspectiva permeie as políticas e diretrizes incorporadas ao Planejamento Estratégico da organização inovadora, aprimorando dessa forma a eficiência dos métodos e ampliando o uso das capacidades ociosas de seus recursos e competências. 


\title{
Patent as a competitive tool and as a source of technological information
}

\begin{abstract}
Current globalized markets, due to their intense competition and several technological innovations, raise two questions: why Brazilian companies do not pay attention to the importance of patents as competitive tools and why do they not consider the exploration of patents as a source of technological information? This paper addresses both issues. A field research was developed to answer four specific questions: What are the motivating and inhibiting factors of the use of patents as competitive tools and what are the motivating and inhibiting factors of the exploration of patents as sources of technological information? In addressing these issues, the relevance of ten motivating and ten inhibiting factors was assessed. A bibliographic review and a preliminary research aimed at the elaboration of an electronic questionnaire, which was distributed among the companies members of ANPEI - Associação Nacional de Pesquisa, Desenvolvimento e Engenharia das Empresas Inovadoras, a Brazilian Association for the innovative enterprises. The answers were recorded in a database, which helped the management of information and allowed the analysis according to company size.
\end{abstract}

Keywords: Industrial property. Patents. Competitive strategy. Technological information.

\section{Referências bibliográficas}

ASSOCIAÇÃO NACIONAL DE PESQUISA E DESENVOLVIMENTO DAS EMPRESAS INOVADORAS - ANPEI. Indicadores Empresariais de Inovação Tecnológica. Disponível em: <www. anpei.org.br>. Acesso em: 07 de Abril de 2005.

ANSOFF, H. I.; McDONNELL, E. J. Implantando a administração estratégica. 2 ed. São Paulo: Atlas, 1993.

AZEVEDO, P. F. Organização Industrial. In: PINHO, D. B. et al. (Orgs.). Equipe de Professores da USP. Manual de Economia. 3 ed. São Paulo: Saraiva, 1999. p. 203-226.

BANNOCK, G.; BAXTER, R. E.; REES R. The penguin dictionary of economics. 2 ed. London: Penguin Books, 1977.

BARATELLI, F.; LEITE, L. F.; COSTA, M. F.; VIEIRA, T. R. S. Administrando o Processo de Inovação Tecnológica. In: XVIII SIMPÓSIO DE GESTÃO DA INOVAÇÃO TECNOLÓGICA, 1994, São Paulo. Proceedings... São Paulo: USP; NPGCT; FIA; PACTo, 1994. p. 117-132

BARNEY, J. Gaining and sustaining competitive advantage. 2 ed. Upper Saddle River: Prentice Hall, 2002.

BORBA, A. L. S. A tecnologia como ferramenta imprescindível para o desenvolvimento. Revista da ABPI, no. 41, p. 45-47, 1999.

CARLOS, J. A. Gestão do conhecimento. São Paulo: Fundação do Desenvolvimento Administrativo - FUNDAP, 2005.

CARVALHO, L. C. P. Teoria da Firma: a produção e a firma. In: PINHO, D. B. et al. (Orgs.). Equipe de Professores da USP: Manual de Economia. 3 ed. São Paulo: Saraiva, 1999. p. $160-190$.

COLlins, G. Collins Portuguese gem dictonary. São Paulo: Collins Clear-Type Press, 1979.

DEPARTAMENTO DE TECNOLOGIA DA FIESP/CIESP. Informação tecnológica e competitividade. São Paulo: DETEC, 1996.

FERNANDES, J. M. Gestão da tecnologia como parte da estratégia competitiva das empresas. Brasília: CIP, 2003.

FERREIRA, A. A.; REIS, A. C. F.; PEREIRA, M. I. Gestão empresarial: de Taylor aos nossos dias - evolução e tendências da Moderna Administração de Empresas. São Paulo: Pioneira Thomson Learning, 1997.
FONSECA, A. Concorrência e propriedade intelectual. Revista da ABPI, no. 36, p. 3-24, 1998.

FUNDAÇÃO SEADE. Manual de orientação para preenchimento de questionários. São Paulo: Rettec, 2002. PAEP - Pesquisa de Atividade Econômica Paulista 200.

GAIARSA, L. M. Experiência de um usuário de patentes. In: XVII SEMINÁRIO NACIONAL DA PROPRIEDADE INDUSTRIAL, 17. Anais... Porto Alegre: ABPI, 1997. p. 59-62.

GUIMARÃES, E. R. Fatores motivadores e inibidores da utilização das patentes como instrumento competitivo e de sua exploração como fonte de informação tecnológica. 2001. 165 p. Dissertação (Mestrado em Administração) - Universidade Paulista, São Paulo.

GWARTNEY, J. D.; STROUP, R. L. Economics private and public choice. 7 ed. Orlando: The Dryden Press, 1995.

INSTITUTO BRASILEIRO DE GEOGRAFIA E ESTATÍSTICA IBGE, PESQUISA DE INOVAÇÃO TECNOLÓGICA - PINTEC. Disponível em: <http://www.pintec.ibge.gov.br>. Acesso em: 21 de Março de 2008.

INSTITUTO NACIONAL DA PROPRIEDADE INDUSTRIAL - INPI. Lei de Propriedade Industrial no 9279 de 14 de maio de 1996. Rio de Janeiro, 1996. Disponível em: <http://www.inpi.gov.br>. Acesso em: 18 de Junho de 2008.

LOBO, T. T. Lei 9.279/96: Introdução à nova Lei de Propriedade Industrial. São Paulo: Atlas, 1997.

MANKIW, N. G. Principles of Economics. Orlando: The Dryden Press, 1995.

LECHUGA, V. M.; IBARRA, R. C. La Gestion de la informacion em la empresa: Su manejo y proteccion por médio de títulos de propriedad intelectual. In: SIMPÓSIO DE GESTÃO DA INOVAÇÃO TECNOLÓGICA, 18., 1994, São Paulo. Anais... São Paulo: USP; NPGCT; FIA; PACTo, 1994. p. 459-469.

NEMMERS, E. E. Dictionary of Economics and Business. New Jersey: Littlefield; Adams \& Co, 1979. 
OFICINA ESPANHOLA DE PATENTES Y MARCAS. Las patentes como fuente de información tecnológica. Madrid: MINER, 1999.

PINTO, A.; FREDES, C. Curso de economia. São Paulo: Forum Editora, 1973

PORTER, M. E. Competitive strategy techniques for analyzing industries and competitors. New York: The Free Press, 1980.
PORTER, M. E. Vantagem competitiva: criando e sustentando um desempenho superior. 7 ed. Rio de Janeiro: Campus, 1985.

SELDON, A.; PENNANCE, F. G. Dicionário de Economia. 3 ed. Rio de Janeiro: Bloch Editora, 1975.

SILVEIRA, N. A propriedade Intelectual e as novas leis autoriais. São Paulo: Saraiva, 1998.

TREIGUER, C. R. O INPI como base de difusão tecnológica. Rio de Janeiro: INPI, 2000.

\section{Sobre os autores}

\section{Ademir Antônio Ferreira}

Programa de Mestrado em Administração

Universidade Paulista - UNIP

Rua Dr. Bacelar, 1212, CEP 04026-002, São Paulo, SP

e-mail: adefer@usp.br

\section{Edílson Rodrigues Guimarães}

Programa de Mestrado em Administração

Universidade Paulista - UNIP

Rua Dr. Bacelar, 1212, $4^{\circ}$ andar, CEP 04026-002, São Paulo, SP

e-mail: edilson@daviddonascimento.com.br

\section{José Celso Contador}

Programa de Mestrado e Doutorado em Administração

Universidade Nove de Julho - UNINOVE

Av. Francisco Matarazzo, 612, CEP 05001-100, São Paulo, SP

e-mail: celsocontador@terra.com.br 